\title{
Dynamic behaviour difference between high- and low-raft forms of piles in earthquakes
}

Hu Qin

Associate Professor, School of Civil Engineering, He Xi University, Zhangye,

China (corresponding author: hxqin_hu@163.com)

\section{Kang Ma}

Professor, School of Civil Engineering, He Xi University, Zhangye, China; National University of Singapore, Singapore

\section{Using centrifuge tests and numerical simulation, this study indicates that the seismic behaviours of piles under high-} and low-raft conditions are quite different. The pile with a high raft is more unfavourable than that with a low raft.

\author{
Notation \\ $a_{\mathrm{b}} \quad$ peak base acceleration \\ c constant multiplier \\ d pile diameter \\ $E_{\mathrm{p}} \quad$ pile material modulus \\ $E_{\mathrm{s}} \quad$ soil deformation modulus \\ $(E)_{\mathrm{p}} \quad$ pile flexural rigidity \\ $m$ raft mass \\ $n \quad$ curve-fitting index \\ $r \quad$ pile radius \\ Z soil depth \\ $\rho \quad$ soil density
}

\section{Introduction}

For a pile-raft foundation, the raft is usually embedded into the foundation soil to share part of the superstructure load; this is the low-raft form which is wildly used in the pile foundations. Due to the later settlement effect of unconsolidated soil or seismic subsidence, the raft may be separated from the soil, and then the form of the pile foundation may change from a low-raft to a high-raft case.

The principal characteristics of this study represent a typical soil-pile interaction (SSPI) problem, mainly including kinematic, inertial and physical interactions and radiation damping. Kinematic interaction is the seismic response of the soil profile transmitted to the pile foundation, which attempts to deform with the soil, resulting in the superstructure experiencing a ground motion different from that of the free-field soil. Inertial interaction consists of structural inertial forces being transferred to the pile foundation. These forces impose lateral loads, which are concentrated near the pile head, and axial loads on the pile. Both axial and lateral loads are usually transmitted by way of the raft, which can be classified into two cases according to the contact condition with foundation soil or not; this is the focus of the present study. Important physical interaction between the pile and soil occurs before and during seismic loading. During initial pile installation and loading, soil displacement, load transfer and downdrag forces set up a unique stress state in the pile and surrounding soil, on which any seismically induced stresses will be superimposed. During seismic loading, gaps may open between the soil and the pile near the ground surface. In cohesionless soils, the gap may be filled in and be compacted; however, in cohesive soils, the gap may stand open, resulting in a reduction in soil-pile lateral stiffness. Radiation damping occurs due to the stiffness contrast between the soil and pile. Piles vibrate at much higher frequencies than the surrounding soil, but soil-pile contact forces the soil to also vibrate at these high frequencies, resulting in the transmission of high-frequency energy away from the pile into the surrounding soil. It is thus evident that SSPI in a non-linear, softening, degrading material is a complex issue that merits serious study, particularly for cases with different raft embedment conditions for pile foundations as in this study.

So far, research methods on the SSPI problem mainly include experiments and numerical simulation: Snyder (2004) carried out in-site quasi-static lateral pile load tests in soft Salt Lake clay. The results of his study showed that soil stiffness degraded with repeated cyclic shearing and plastic deformation of soil surrounding the pile. Studies using dynamic shaking table tests in a $1 \mathrm{~g}$ field indicate that in comparison with a pile group, a piled raft foundation generates less bending moment in piles and horizontal displacement (Matsumoto et al., 2004; Yuksekol et al., 2015). Centrifuge model tests using shaking tables have been widely conducted. The test results indicated significant kinematic loading from the soil to the supporting piles, inducing large bending moments at the pile heads (Banerjee, 2009; Banerjee et al., 2014; Boulanger et al., 1999; Kang et al., 2012; Liu and Dobry 1995; Meymand, 1998; Zhang et al., 2016). The development of bending moment in piles has been found to be influenced more by ground movement than inertial loading from the superstructure (Yamashita et al., 2012, 2016). Besides experiments, numerical simulation is also an important means of investigating the SSPI problem. Huang et al. (2004) proposed a three-dimensional (3D) effective stress finite-element method to predict the earthquake response of pile foundations. Khodair and Hassiotis (2005) incorporated non-linear soil-pile interaction into a 3D finite-element model using the finite-element software Abaqus. Their results showed that the bending stresses along the pile calculated by the finite-element model agreed well with those measured from a fully instrumented bridge and the results from finite-difference computation. Mayoral et al. (2009) compared the actual seismic response of an urban bridge support system consisting of a box foundation with piles on soft clay with computed results using two-dimensional models in the substructure-based Sassi program. Mayoral and Romo (2015) carried out 3D seismic response analysis of a bridge support and a centrifuge model. Varghese et al. (2019) presented a paper on 3D 
seismic soil-structure interaction analysis of a piled-raft foundation in clay by the substructure approach. Most of these studies were mainly focused on the dynamic analysis of a certain pile form, and the form of a high- or low-raft case is still not distinguished. There exists a lack of relevant research on the difference in seismic behaviour between high- and low-raft cases for the pile foundations. The current design codes or relevant technical manuals (such as Eurocode 8: Part 5 (BSI, 2004)) on pile foundations roughly estimate the effect for the embedded raft case - that is, considering only several factors such as the ratio of the pile space to diameter and the ratio of the raft width to pile length, and combined with the engineering experience, the efficiency coefficient of soil interaction between piles is suggested.

In this study, the problem of soil-pile-raft interaction for the two pile cases of high- and low-raft conditions during earthquakes will be examined using an experimental approach involving seismic centrifuge model tests and numerical simulation using the Abaqus software. The main objective of the study is to understand the difference in pile seismic behaviour arising from the change in the raft embedment condition, which affects the resonance period of soil and foundation (raft), and, more importantly, its effects on the maximum bending moment as well as the active length of the pile.

\section{Materials and methods}

In this study, the material used for the pile-raft structure is made of stainless steel, and the soil is normally consolidated kaolin clay widely distributed in Singapore. The raft is supported by four piles with heads fixed into the raft. The pile is $13 \mathrm{~m}$ long and has a diameter of $0.5 \mathrm{~m}$. According to the different prepared soil thicknesses, the high- or low-pile-raft cases can be distinguished. The centrifuge shaking table tests and Abaqus numerical simulation are adopted for this study.

\section{Centrifuge model tests}

The model layout and sensor positions are shown in Figure 1. Accelerometer A1 is installed at the soil bottom to measure the input seismic acceleration time history, while A2 is for measuring the time history of the soil surface (including high- and low-pile-raft cases). Accelerometer A3 is fixed on the raft surface to measure the seismic acceleration of foundation. Moreover, five strain gauges S1-S5 spaced by $2.5 \mathrm{~m}$ are installed at different depths along the pile body to measure the bending moment. The pile-raft-soil model (after soil pre-consolidation) before seismic tests is shown in Figure 2. Because the pile spacing here is more than $9 d$, the single pile foundation is studied. The test acceleration level is 50g. An additional steel block is loaded on the raft (load1-load3) to simulate the load effect from the superstructure to the pile, as shown in Table 1 . To reveal the influence of earthquake intensity and duration on the seismic behaviour of the pile-raft-soil system, each test earthquake excitation series is composed of three consecutive seismic events of small, medium and large earthquakes. The frequency spectra of the three seismic events are the same and only scaled in proportion. The peak ground accelerations (PGAs) are $0.022 \mathrm{~g}, 0.052 \mathrm{~g}$ and $0.13 \mathrm{~g}$, respectively, and the duration of each

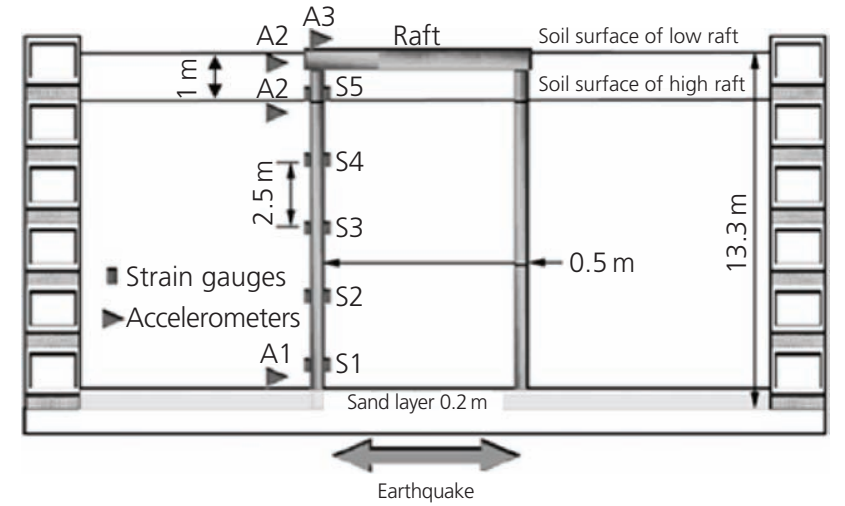

(a)

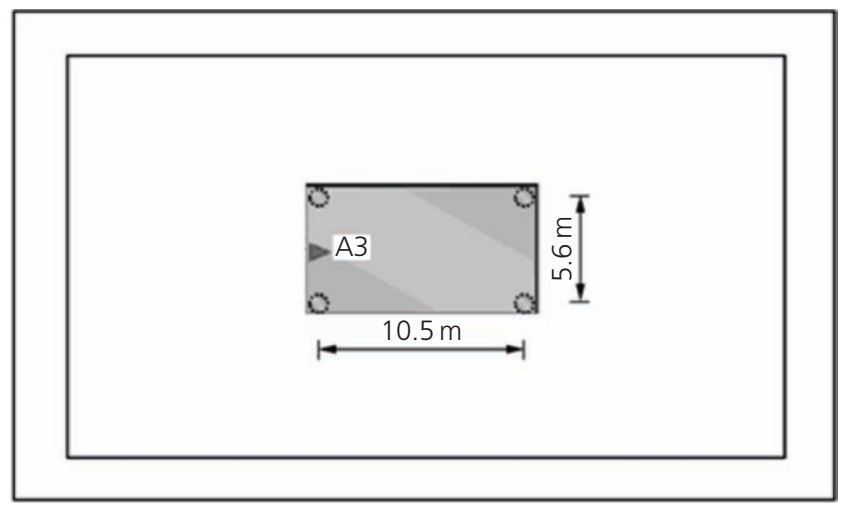

(b)

Figure 1. Centrifuge tests for high- or low-raft cases and sensor arrangement: (a) test scheme of pile foundation; (b) sensor arrangement

earthquake event is $25 \mathrm{~s}$ as shown in Figure 3. Other centrifuge test details can be seen in the publication by Kang et al. (2012).

\section{Abaqus numerical simulation}

Consistent with the aforementioned centrifuge tests for high- and low-raft cases, the Abaqus program was used to verify this problem. The corresponding Abaqus model (symmetrical half model) was built as shown in Figure 4. The clay constitutive behaviour was modelled as a hypoelastic model embedded in the Abaqus program. In this study, the strain-dependent stiffness was adopted from the shear modulus-against-shear strain curve in the paper by Vucetic (1988). To simulate laminar box movement in centrifuge tests, linear multi-point constraints were applied to the two vertical faces normal to the earthquake motion to make the nodes at opposite ends of the domain and at the same depth move in unison with each other. Additionally, vertical displacement restraints were applied at all four vertical faces, while the bottom of the model was constrained against vertical movement. A symmetry displacement boundary was additionally applied to the middle plane of the model. The input earthquake was prescribed at the base of the model in the form of an acceleration time history, which was taken from the centrifuge accelerations at the base of the clay bed (recorded by accelerometer A1), from the small, medium and large earthquakes. 
Dynamic behaviour difference between high- and low-raft forms of piles in earthquakes

Qin and Ma

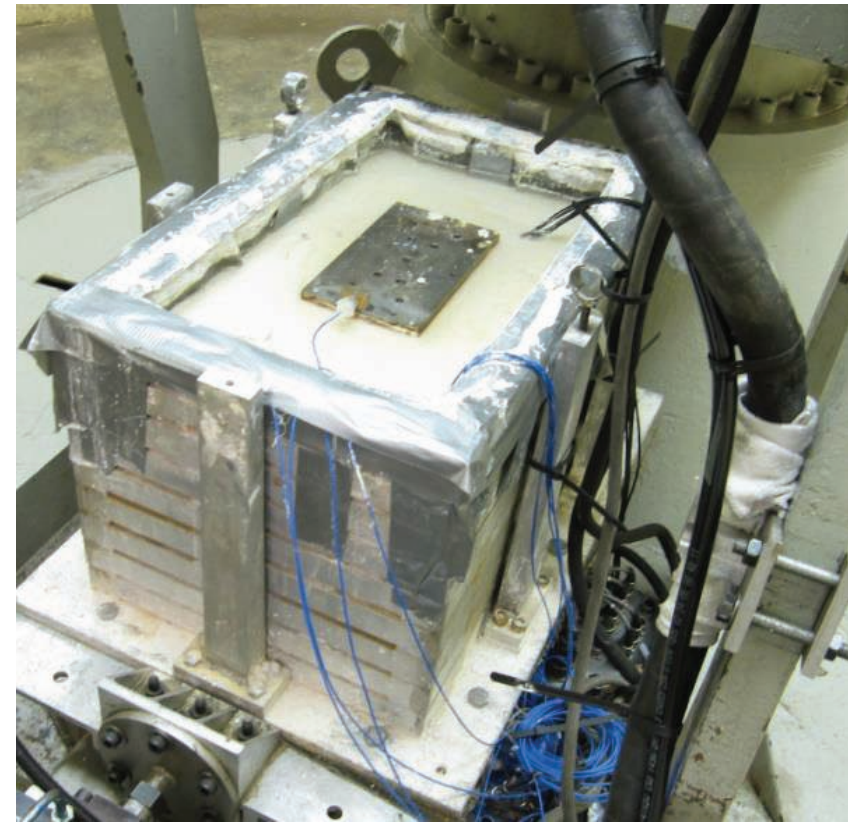

(a)

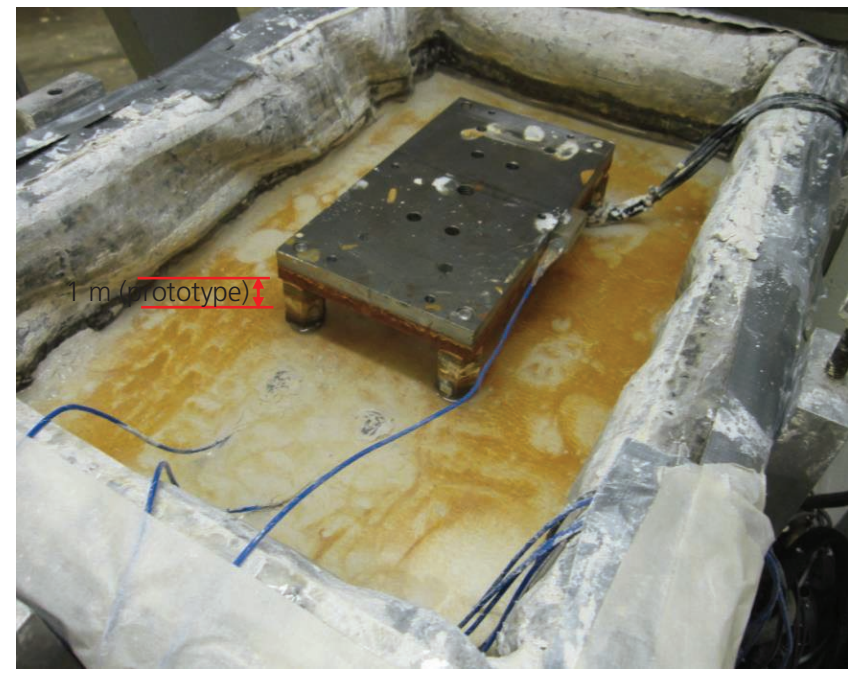

(b)

Figure 2. Pile-raft-soil model after consolidation: (a) low-raft case; (b) high-raft case

\section{Results and discussion}

Period of the foundation (raft)

The period corresponding to the maximum amplification effect (i.e. the maximum ratio of the response spectrum of the soil

Table 1. Cases for different superstructure loading simulations

\begin{tabular}{|cccc|}
\hline $\begin{array}{l}\text { Load } \\
\text { cases }\end{array}$ & Load level & $\begin{array}{c}\text { Model raft } \\
\text { mass: } \mathbf{k g}\end{array}$ & $\begin{array}{c}\text { Prototype raft } \\
\text { mass: kg }\end{array}$ \\
\hline Load1 & Raft & 2.95 & 368000 \\
Load2 & Raft +1 block & 4.84 & 605000 \\
Load3 & Raft + 2 blocks & 6.90 & 863000
\end{tabular}

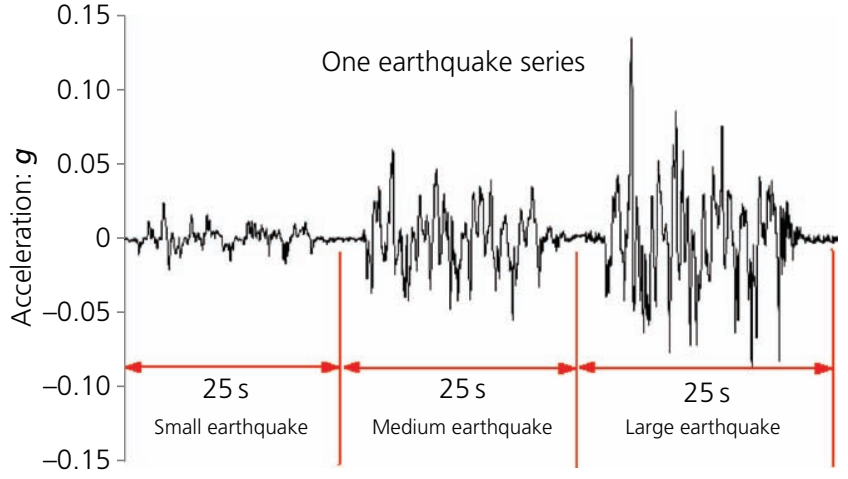

Figure 3. Sequential triggered earthquake events for each centrifuge test

surface (accelerometer A2) or foundation (raft, accelerometer A3) to the input response spectrum of the soil bottom (accelerometer A1)) measured from the centrifuge acceleration time history is defined as the resonance period (Figures 5 and 6).

For a given test condition (such as PGA $=0.052 \boldsymbol{g}$, load2), the acceleration time histories (Figures 5(b) and 5(c)) measured from the same seismic input from the soil bottom (Figure 5(a)) are not completely the same, which indicates that the seismic responses of the two types of pile are different. Figure 6 shows the corresponding response spectra (damping ratio 5\%) of the two types of pile foundations. Although the response spectrum forms and the obtained periods (about 2.0 and $2.1 \mathrm{~s}$ ) are very close for the two cases, there still exist some differences. It is proven again that the seismic responses of the two pile cases are different, which inevitably lead to the difference in the seismic behaviour of the superstructure. Periodic variation plots under three kinds of PGAs and three load cases are summarised in Figure 7.

It can be seen from Figure 7 that, although there are differences between the test and Abaqus results, their overall trends are still close to each other. For the condition of the high-raft case, its foundation (raft) period is obviously higher than that of the corresponding low-raft case. This is mainly due to the separation between the raft and soil surface, which leads to the release of contact between them; subsequently, the restraint effect on the whole pile-raft system would be weakened. As a result, the lateral stiffness of the whole foundation structure is reduced, so the period will be prolonged. Therefore, in view of the change in pile-raft foundation embedment conditions, the foundation period will be extended to a large extent, which is similar to the seismic effect of a deep soft soil site, particularly unfavourable for longperiod high-rise structures.

\section{Bending moment of piles}

Figure 8 summarises the bending moment envelope diagrams of piles with high- and low-raft cases under three seismic intensities and three load levels. Although there are differences between the test results 
Dynamic behaviour difference between high- and low-raft forms of piles in

earthquakes

Qin and Ma

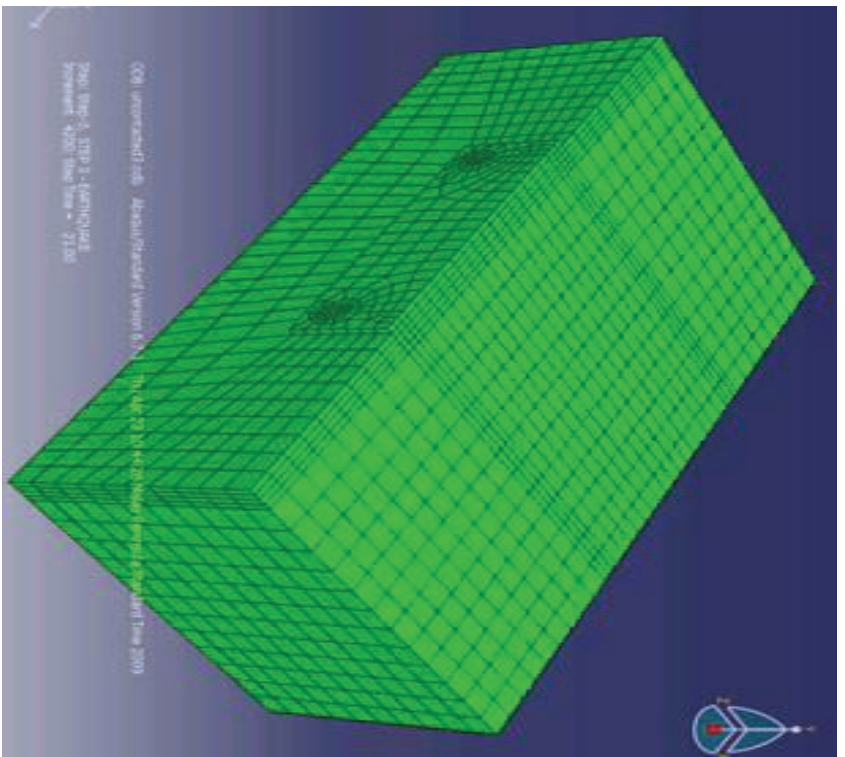

(a)

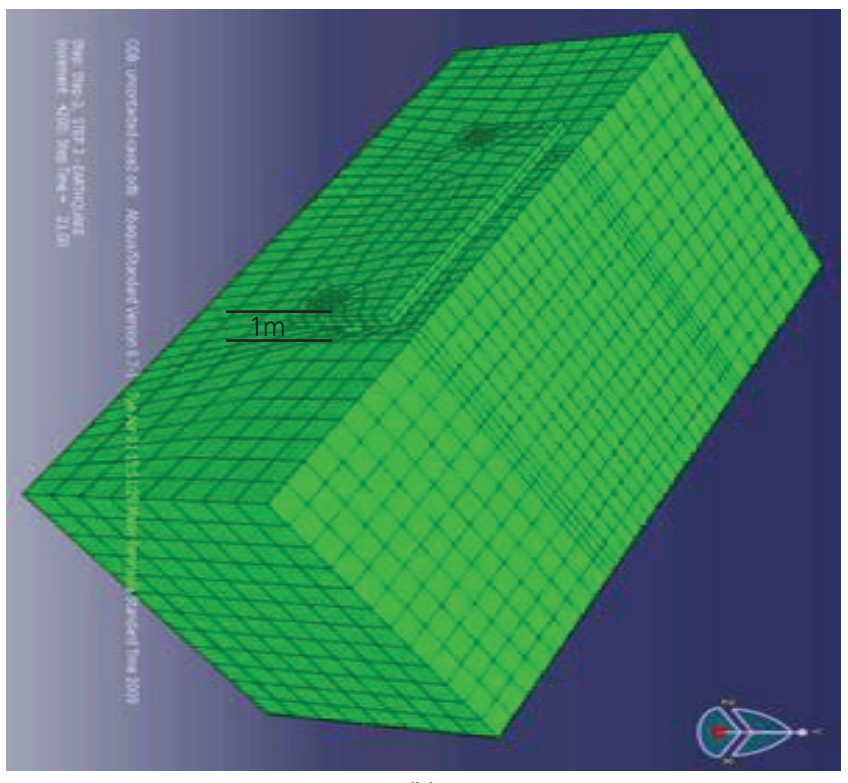

(b)

Figure 4. Abaqus models for high- and low-raft cases of the pile foundation: (a) low-raft model; (b) high-raft model

and Abaqus calculation results, they are basically consistent with each other in terms of value, sign and variation rule. Obviously, when the earthquake intensity is relatively weak $(\mathrm{PGA}=0.022 \mathrm{~g})$, the maximum bending moment of the pile for the high-raft case (strain gauge S5) is smaller than that of the low-raft case. When the seismic intensity gradually increases (PGA $=0.052 \mathrm{~g}$ ), the maximum bending moment values of the two pile cases are very close. When the earthquake intensity is further strengthened (PGA $=0.13 g$ ), the maximum bending moment of the pile under the high-raft case is significantly greater than that of the corresponding low-raft case. According to the centrifuge test results, for load1-load3, the

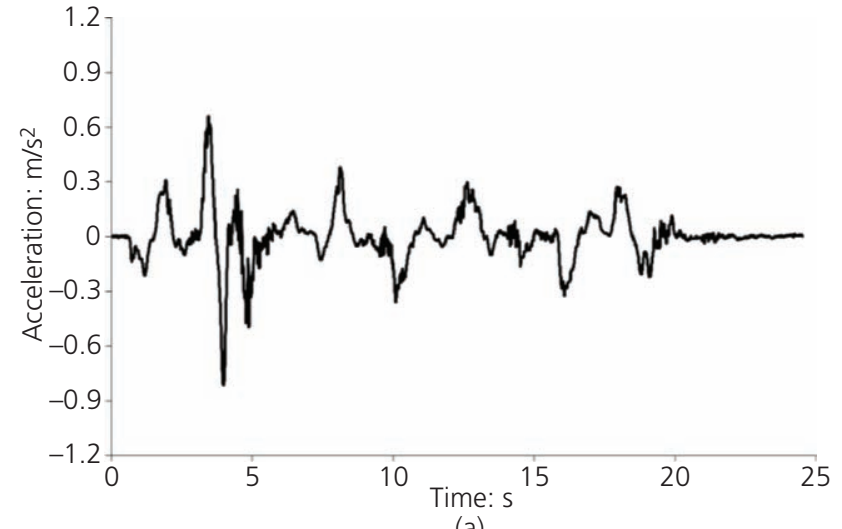

(a)

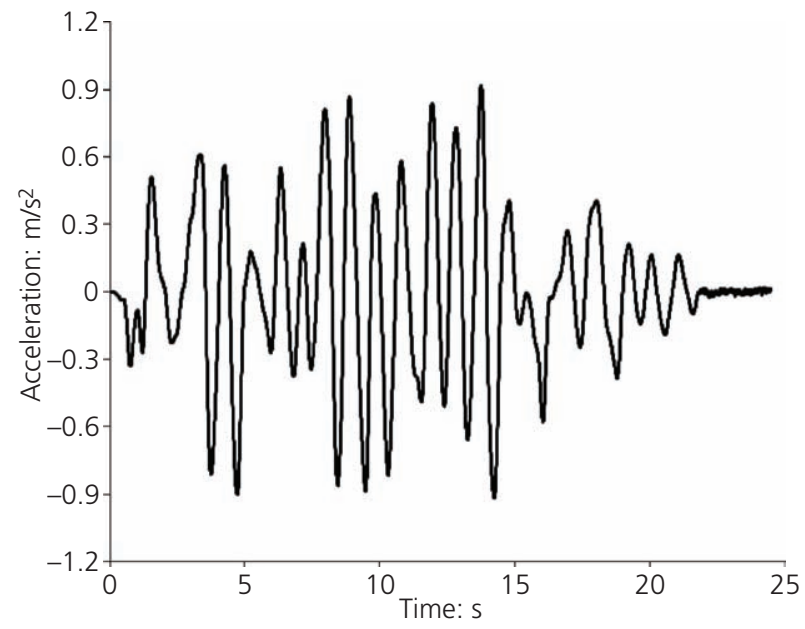

(b)

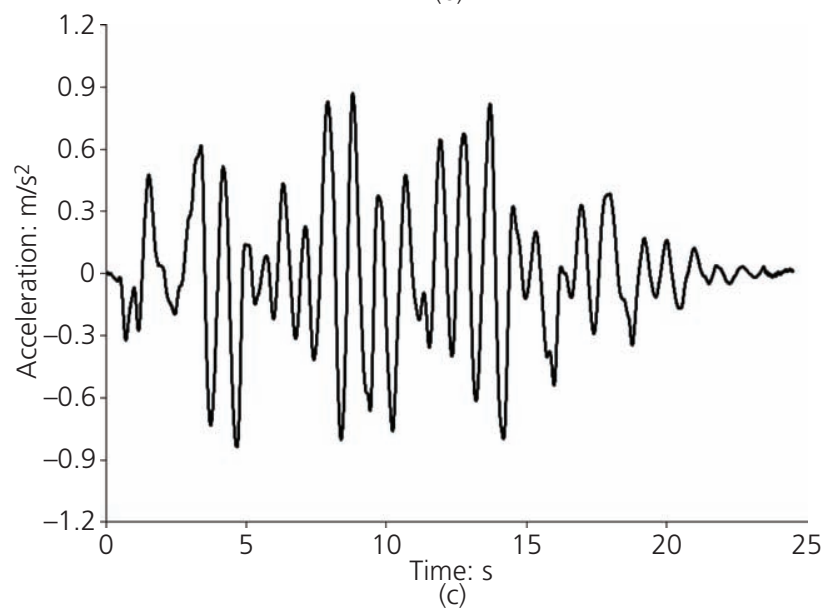

Figure 5. Time-history curves of the measured acceleration in typical earthquake shaking tests: (a) acceleration time history measured from the soil bottom (accelerometer A1);

(b) acceleration time history measured from the raft of the high-raft case (accelerometer A3); (c) acceleration time history measured from the raft of the low-raft case (accelerometer A3)

maximum bending moments of the low raft-pile foundation are about 557, 677 and $809 \mathrm{kN} \mathrm{m}$, respectively, and the corresponding values of the high raft-pile are about 908,947 and $1058 \mathrm{kN} \mathrm{m}$, 


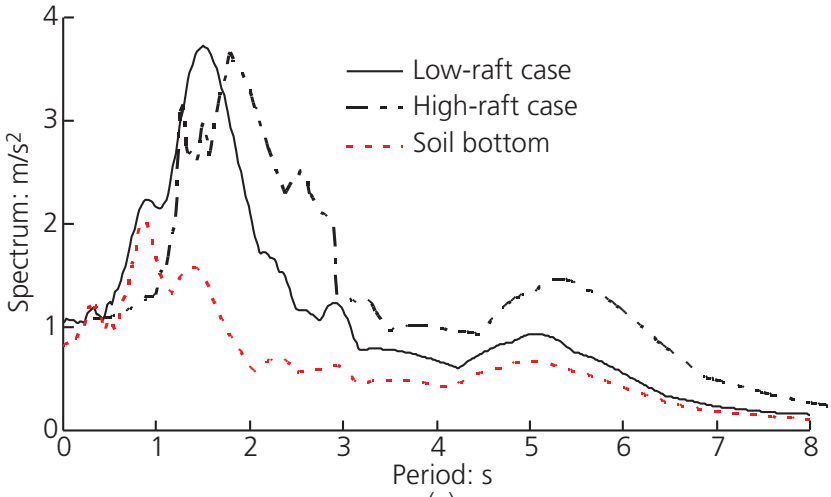

(a)

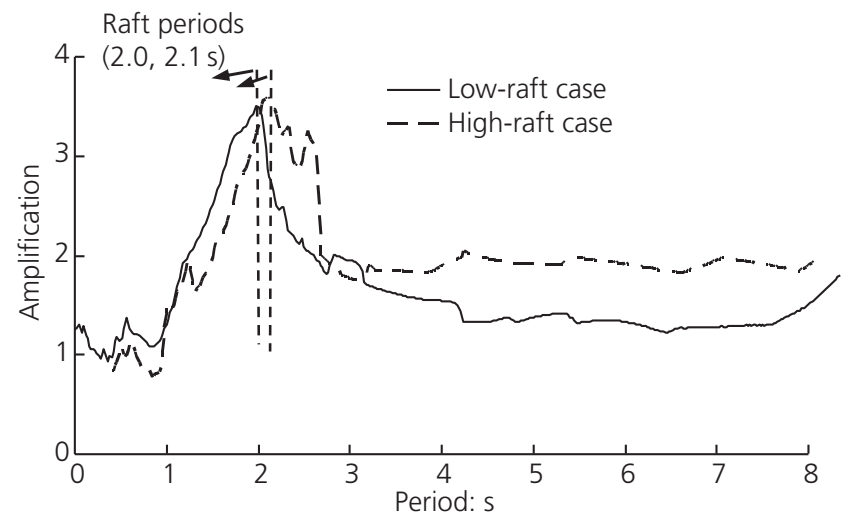

(b)

Figure 6. Raft periods and amplifications from tests: (a) raft (A3) and soil bottom (A1) acceleration response spectra;

(b) amplifications of the soil surface (A2)

which are increases of about 63,40 and $31 \%$, respectively. It can be concluded from this changing trend that when the earthquake intensity is strong (usually greater than $0.15 \mathrm{~g}$ ), the peak moment of the pile foundation may increase significantly. If the pile foundation was designed according to the condition of a low-raft case, it would be unsafe, which could be seen in many earthquake damage investigations. Moreover, the effective depth $l_{\mathrm{a}}$ of the bending moment for a high-raft case is deepened because of the contact release between the raft and soil; that is to say, the pile can still produce a significantly large bending moment in a deeper range, which is more obvious when the loading level is large. This is quite different from the bending moment distribution characteristics of a low-raft case.

\section{Comparison with other results}

Gazetas (1984) proposed formulas for calculating the effective depth $l_{\mathrm{a}}$ of a pile based on different soil models. These are summarised in Table 2 along with the centrifuge test results from this study. It can be seen that if the form of a pile foundation with a high- or low-raft case is not distinguished - that is, according to the formula given by Gazetas - the effective depth of the pile studied in this paper should be between 5.10 and $6.43 \mathrm{~m}$. However, the effective depths of the bending moment of the two types of piles revealed by the centrifuge test herein are completely different. The pile with a low raft is about $4.2-4.5 \mathrm{~m}$, while the pile with a highraft case is about $4.5-8.8 \mathrm{~m}$. The difference between them is very significant, so this cannot be considered a uniform case. The influence depth of the bending moment of the pile with a high-raft condition is deeper. If the preliminary pile design is done according to the low-raft case in terms of the relevant code, with stirrups only closely added at a certain limited depth near the pile head to resist seismic shear action, this may be unsafe for the later evolutionary high-raft case. Consequently, due to various factors, such as the rheology of foundation soil, seismic subsidence, blasting or surcharge, the seismic performance of the pile foundation will be weakened, the peak bending moment will increase and the effective depth will be deepened, and the adverse effects should be fully considered in the earlier seismic design.

Banerjee et al. (2014) presented a formula for calculating the maximum bending moment in flexible piles; this is summarised in Table 3 along with the results obtained from centrifuge tests in this study. It is obvious that for different load cases (load1-load3), the maximum bending moments $M_{\max }$ of a pile predicted from Banerjee et al.'s equation are about 601,705 and $821 \mathrm{kN} \mathrm{m}$, respectively, while the value of $M_{\max }$ in this study is not fixed because of distinguishing different forms of high- and low-pile cases. Under the low-raft case, the $M_{\max }$ values of the pile are about 557, 677 and $809 \mathrm{kN} \mathrm{m}$ for the three load cases, which are very close to the results of Banerjee et al. However, when the pile foundation changes into a

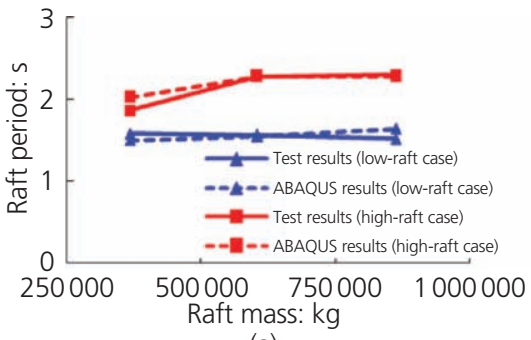

(a)

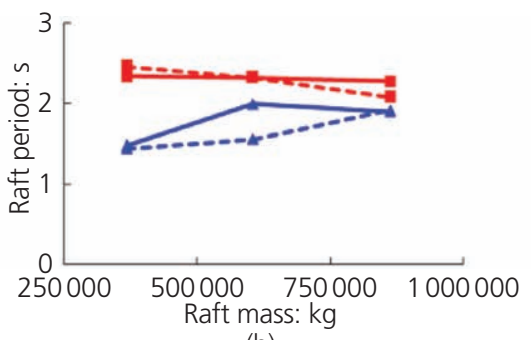

(b)

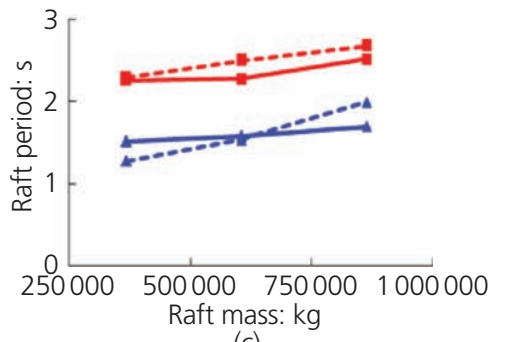

(c)

Figure 7. Contrast of summarised periods for both high and low raft-pile foundations: (a) small earthquake (PGA = 0.022 g); (b) medium earthquake $(P G A=0.052 \boldsymbol{g})$; $(c)$ large earthquake $(P G A=0.13 \boldsymbol{g})$ 

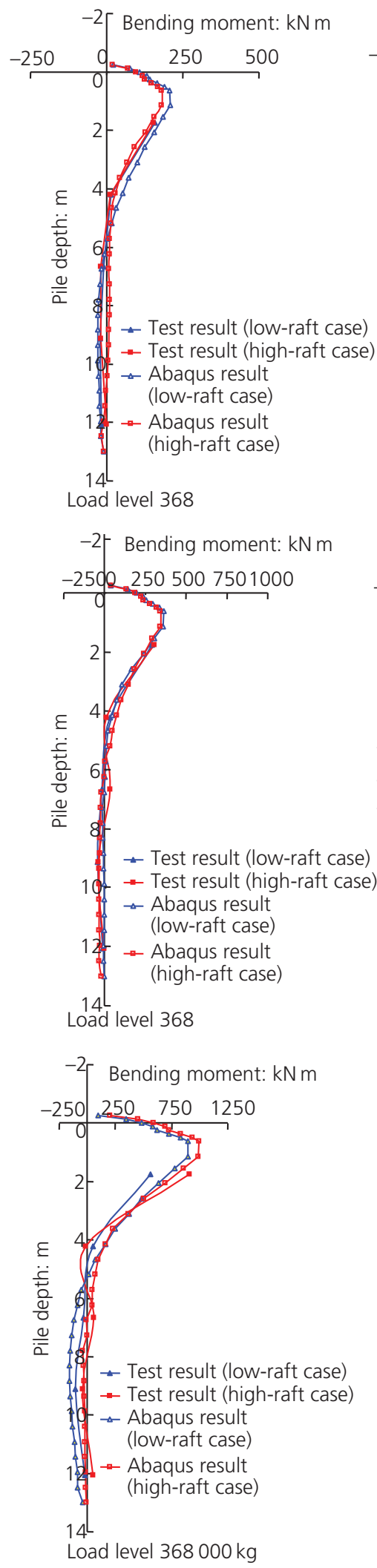

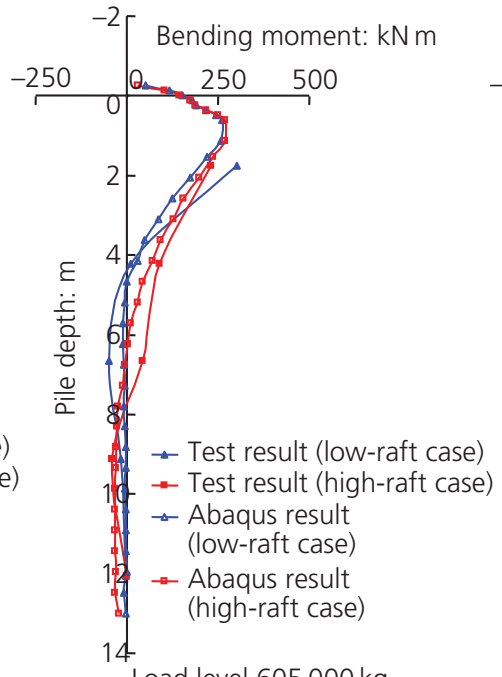

(a)

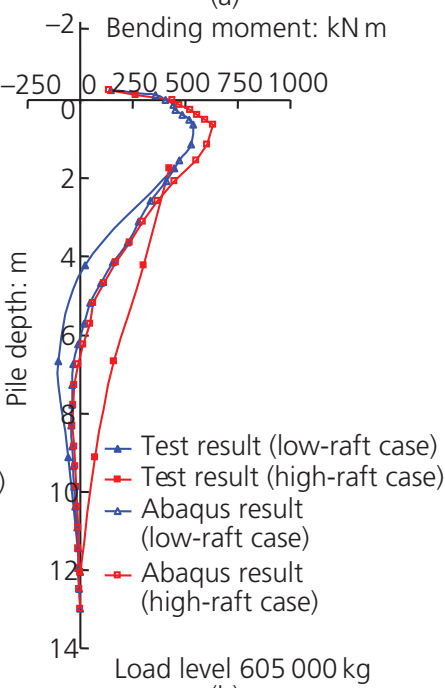

(b)

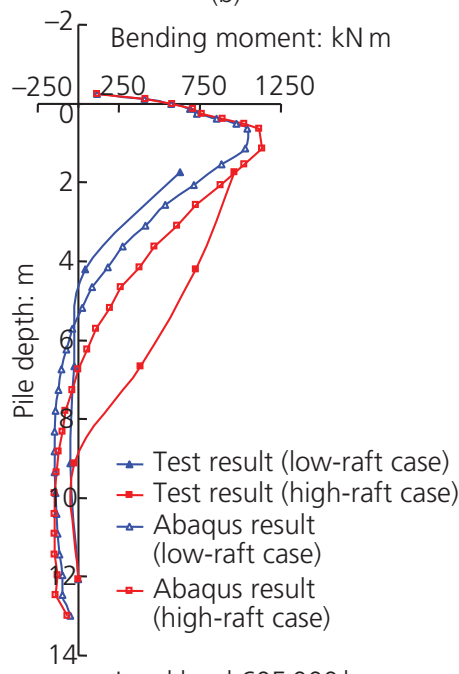

Load level $605000 \mathrm{~kg}$

(c)
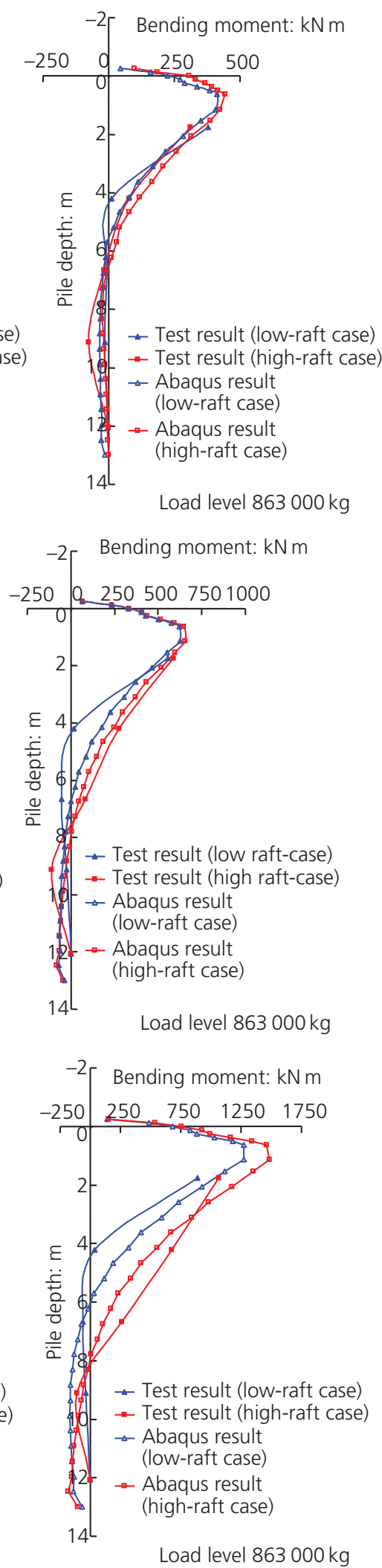

Figure 8. Envelope diagrams of the bending moment of piles under different PGA and load levels: (a) PGA =0.022 $\boldsymbol{g}$; (b) PGA =0.052 $\boldsymbol{g}$; (c) $P G A=0.13 g$ 
Table 2. Pile active length $/ a$

\begin{tabular}{|c|c|c|c|c|}
\hline \multirow{2}{*}{ Soil model } & \multirow{2}{*}{ Formula of Gazetas (1984) } & \multirow{2}{*}{$l_{\mathrm{a}}$ from Gazetas's formula: $\mathrm{m}$} & \multicolumn{2}{|c|}{ This study's test results: $\mathrm{m}$} \\
\hline & & & Low-raft case & High-raft case \\
\hline $\begin{array}{l}E=E_{\mathrm{s}} z / d \\
E=E_{\mathrm{s}}(z / d)^{0.5} \\
E=E_{\mathrm{s}}\end{array}$ & $\begin{array}{l}l_{\mathrm{a}}=3.2 d\left(E_{\mathrm{p}} / E_{\mathrm{s}}\right)^{1 / 6} \\
l_{\mathrm{a}}=3.2 d\left(E_{\mathrm{p}} / E_{\mathrm{s}}\right)^{2 / 11} \\
I_{\mathrm{a}}=3.3 d\left(E_{\mathrm{p}} / E_{\mathrm{s}}\right)^{1 / 5}\end{array}$ & $\begin{array}{l}5.10 \\
5.66 \\
6.43\end{array}$ & $4.2-4.5$ & $4.5-8.8$ \\
\hline
\end{tabular}

$d$, pile diameter; $E_{\mathrm{p}}$, pile material modulus; $E_{\mathrm{s}}$, soil deformation modulus; $z$, soil depth

Table 3. Maximum bending moment $M_{\max }$ of the pile

\begin{tabular}{|c|c|c|c|c|}
\hline \multirow{2}{*}{ Load case } & \multirow{2}{*}{ Equation of Banerjee et al. (2014) } & \multirow{2}{*}{$M_{\max }$ from Banerjee et al.'s equation: $\mathrm{kN} \mathrm{m}$} & \multicolumn{2}{|c|}{ This study's test results: $\mathbf{k N ~ m}$} \\
\hline & & & Low-raft case & High-raft case \\
\hline $\begin{array}{l}\text { Load1 } \\
\text { Load2 } \\
\text { Load3 }\end{array}$ & $\frac{M_{\text {max }} r}{(E)_{\mathrm{p}}}=0.01\left(\frac{a_{\mathrm{b}}}{\mathrm{g}}\right)^{0.67}\left(\frac{E_{\mathrm{ep}}}{c r^{n}}\right)^{-0.57}\left(\frac{\mathrm{m}}{\rho r^{3}}\right)^{0.434}$ & $\begin{array}{l}601 \\
705 \\
821\end{array}$ & $\begin{array}{l}557 \\
677 \\
809\end{array}$ & $\begin{array}{r}908 \\
947 \\
1058\end{array}$ \\
\hline
\end{tabular}

$a_{\mathrm{b}}$, peak base acceleration; $c$, constant multiplier 7228.53 ; $(E I)_{\mathrm{p}}$, pile flexural rigidity; $m$, raft mass; $n$, curve-fitting index 0.653 for normally consolidated kaolin clay; $r$, pile radius; $\rho$, soil density

high-raft case, there is a large increase in the maximum bending moment of the pile, with values of 908,947 and $1058 \mathrm{kN} \mathrm{m}$, which the equation proposed by Banerjee et al. no longer satisfies appropriately. Therefore, their research results may be applied only to low-raft-pile foundation cases, not to all types of pile foundations.

\section{Conclusion}

- The embedment condition of the raft has a great influence on the seismic behaviour of the pile foundation. The seismic responses for two forms - high- or low-raft condition should be studied separately and cannot be confused and considered as a single case in the design.

- The pile foundation with a low-raft case adopted according to earlier design may develop into the form of a high-raft case in the later stage, and the key indexes such as the foundation (raft) period, maximum bending moment and effective depth of pile are more unfavourable than those under the corresponding low-raft conditions. The results indicated that the pile will undergo a higher maximum bending moment and a much larger active depth under the high-raft case than under the low-raft case. Moreover, the foundation (raft) period is significantly prolonged compared with that of the corresponding low-raft case.

- Due to the different seismic behaviours of high- and low-raft cases, enough attention should be paid to the settlement caused by the change in foundation and surrounding geotechnical environment after the pile foundation construction.

- For a pile foundation in sandy soil, the main seismic failure mechanism is liquefaction and large deformation of lateral expansion foundation. At present, there are many research results that can be used for reference. This paper studies a pile foundation in cohesive soil, which may not be applicable to sandy soil conditions.

\section{REFERENCES}

Banerjee S (2009) Centrifuge and Numerical Modelling of Soft Clay-Pile-Raft Foundations Subjected to Seismic Shaking. PhD thesis, National University of Singapore, Singapore.

Banerjee S, Goh SH and Lee FH (2014) Earthquake-induced bending moment in fixed-head piles in soft clay. Géotechnique 64(6): 431-446, https://doi.org/10.1680/geot.12.P.195.

Boulanger RW, Curras CJ, Kutter BL, Wilson DW and Abghari A (1999) Seismic soil-pile-structure interaction experiments and analyses. Journal of Geotechnical Engineering 125(9): 345-369, https://doi.org/ 10.1061/(ASCE)1090-0241(1999)125:9(750).

BSI (2004) BS EN 1998-5:2004: Eurocode 8. Design of structures for earthquake resistance. Foundations, retaining structures and geotechnical aspects. BSI, London, UK.

Gazetas G (1984) Seismic response of end-bearing single piles. Soil Dynamics and Earthquake Engineering 3(2): 82-93, https://doi.org/0. 1016/0261-7277(84)90003-2.

Huang Y, Zhang F, Yashima A et al. (2004) Three-dimensional numerical simulation of pile-soil seismic interaction in saturated deposits with liquefiable sand and soft clay. Proceedings of Computational Mechanics WCCM VI in Conjunction with APCOM'04, Beijing, China, pp. 165-169.

Kang M, Banerjee S, Lee FH and Xie HP (2012) Dynamic soil-pile-raft interaction in normally consolidated soft clay during earthquakes. Journal of Earthquake and Tsunami 6(3): 251-257, https:doi/org/10. 1142/S1793431112500315.

Khodair Y and Hassiotis S (2005) Analysis of soil-pile interaction in integral abutment. Computers and Geotechnics 32(3): 201-209, https://doi.org/10.1016/j.compgeo.2005.01.005.

Liu L and Dobry R (1995) Effect of liquefaction on lateral response of piles by centrifuge model tests. NCEER Bulletin, January, pp. 143-149.

Matsumoto T, Fukumura K, Horikoshi K and Oki A (2004) Shaking table tests on model piled rafts in sand considering influence of superstructures. International Journal of Physical Modelling in Geotechnics 4(3): 21-38, https://doi.org/10.1680/ijpmg.2004.040302.

Mayoral J and Romo M (2015) Seismic response of bridges with massive foundations. Soil Dynamics and Earthquake Engineering 71: 88-99, https://doi.org/10.1016/j.soildyn.2015.01.008.

Mayoral J, Alberto Y, Mendoza M and Romo M (2009) Seismic response of an urban bridge-support system in soft clay. Soil Dynamics and Earthquake Engineering 29(5): 925-938, https://doi.org/10.1016/j. soildyn.2008.10.007. 
Geotechnical Research

Volume 8 Issue 3
Dynamic behaviour difference between

high- and low-raft forms of piles in

earthquakes

Qin and $\mathrm{Ma}$
Meymand P (1998) Shaking Table Scale Model Tests of Nonlinear Soil-Pile-Superstructure Interaction in Soft Clay. $\mathrm{PhD}$ thesis, University of California, Berkeley, CA, USA.

Snyder JL (2004) Full Scale Test Lateral Load Tests of a $3 \times 5$ Pile Group in Soft Clays and Silts. MSc thesis, Brigham Young University, Provo, UT, USA.

Varghese R, Boominathan A and Subhadeep B (2019) Seismic response characteristics of a piled raft in clay. Journal of Earthquake and Tsunami 13(1): 195-200, https://doi.org/10.1142/S1793431119500052.

Vucetic M (1988) Normalised behaviour of offshore clay under uniform cyclic loading. Canadian Geotechnical Journal 25(6): 33-41, https:// doi.org/10.1016/0148-9062(88)91028-5.

Yamashita K, Hamada J, Onimaru S and Higashino M (2012) Seismic behavior of piled raft with ground improvement supporting a base-isolated building on soft ground in Tokyo. Soils and Foundations 52(5): 1000-1015, https://doi.org/10.1016/j.sandf.2012.11.017.

Yamashita K, Hamada J and Tanikawa T (2016) Static and seismic performance of a friction piled raft combined with grid-form deep mixing walls in soft ground. Soils and Foundations 56(3): 559-573, https://doi.org/10.1016/j.sandf.2016.04.020.

Yuksekol Y, Matsumoto T and Shimono S (2015) Shaking table tests of piled raft and pile group foundations in dry. Proceedings of the 6th International Conference on Earthquake Geotechnical Engineering (ICEGE), Christchurch, New Zealand, pp. 101-106.

Zhang L, Goh S and Liu H (2016) Seismic response of pile-raft-clay system subjected to a long-duration earthquake: centrifuge test and finite element analysis. Soil Dynamics and Earthquake Engineering 92(5): 488-502, https://doi.org/10.1016/j.soildyn.2016.10.018.

\section{How can you contribute?}

To discuss this paper, please submit up to 500 words to the editor at journals@ice.org.uk. Your contribution will be forwarded to the author(s) for a reply and, if considered appropriate by the editorial board, it will be published as a discussion in a future issue of the journal. 